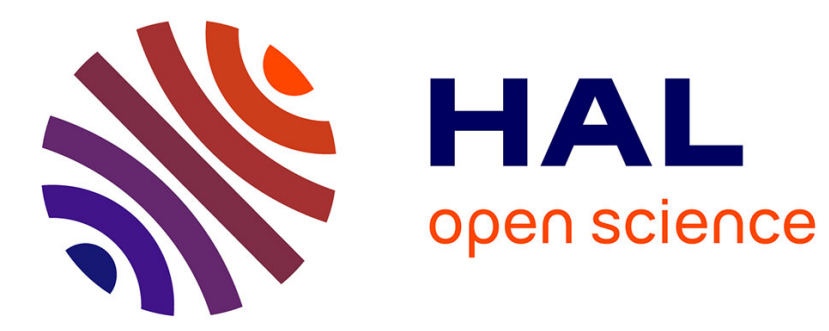

\title{
Effect of oxygen pressure on the structural and magnetic properties of thin $\mathrm{ZnMnO}$ films
}

\author{
A. Khodorov, A.G. Rolo, El-Kebir Hlil, J. Ayres de Campos, O. Karzazi, S. \\ Levichev, M.R. Correia, A. Chahboun, M.J.M. Gomes
}

\section{- To cite this version:}

A. Khodorov, A.G. Rolo, El-Kebir Hlil, J. Ayres de Campos, O. Karzazi, et al.. Effect of oxygen pressure on the structural and magnetic properties of thin ZnMnO films. European Physical Journal: Applied Physics, 2012, 57 (1), pp.10301. 10.1051/epjap/2011110380 . hal-00759672

\section{HAL Id: hal-00759672 \\ https://hal.science/hal-00759672}

Submitted on 2 Dec 2012

HAL is a multi-disciplinary open access archive for the deposit and dissemination of scientific research documents, whether they are published or not. The documents may come from teaching and research institutions in France or abroad, or from public or private research centers.
L'archive ouverte pluridisciplinaire HAL, est destinée au dépôt et à la diffusion de documents scientifiques de niveau recherche, publiés ou non, émanant des établissements d'enseignement et de recherche français ou étrangers, des laboratoires publics ou privés. 


\title{
Effect of oxygen pressure on the structural and magnetic
}

\section{properties of thin $\mathrm{Zn}_{0.98} \mathrm{Mn}_{0.02} \mathrm{O}$ films}

\author{
A. Khodorov ${ }^{1}$, A. G. Rolo ${ }^{1}$, E. K. Hlil ${ }^{2}$, J. Ayres de $\operatorname{Campos}^{1}$, O. Karzazi ${ }^{1,4}$, S. Levichev ${ }^{1}$, M. \\ R. Correia ${ }^{3}$, A. Chahboun ${ }^{1,5}$, and M. J. M. Gomes ${ }^{1}$ \\ ${ }^{1}$ Centro de Física, Universidade do Minho, 4710-057 Braga, Portugal \\ ${ }^{2}$ Institut Néel, CNRS, Université J. Fourier, BP 166, 38042 Grenoble, France \\ ${ }^{3}$ Physics Department and I3N, University of Aveiro, 3810-193 Aveiro, Portugal \\ ${ }^{4}$ LPS, Physics department, Faculty of Sciences, Fès, Morocco \\ ${ }^{5}$ Physics department, FSTT, BP 416 Ziaten, Tanger, Morocco
}

Corresponding author: chahboun@fisica.uminho.pt

\begin{abstract}
:
Thin $\mathrm{Zn}_{0.98} \mathrm{Mn}_{0.02} \mathrm{O}$ films were grown by pulsed laser deposition on glass substrates under oxygen pressure. The structural properties were studied by X-rays diffraction and Raman techniques, while the conductivity was characterized by Hall effect. The oxygen pressure during the growth seems to govern the structural and the electrical properties of the thin $\mathrm{Zn}_{0.98} \mathrm{Mn}_{0.02}$ films. In fact, the micron size grain and the resistivity of the $\mathrm{Zn}_{0.98} \mathrm{Mn}_{0.02} \mathrm{O}$ increase with the partial oxygen pressure. However, no evident effect was observed on the magnetic behavior. Electronic structure calculations were performed and magnetic moment carried by $\mathrm{Mn}$ atom was computed as well.
\end{abstract}




\section{Introduction:}

The use of both charge and spin degrees of freedom in semiconductors is expected to enable a revolutionary class of electronics whose functionality will surpass existing semiconductor technology. Spin electronics combines semiconductor microelectronics with spin-dependent effect that arises from the interaction between electrons and magnetic field. $\mathrm{ZnO}$ based materials have shown a big potential for spintronic applications [1-3]. ZnO thin films are attracting considerable attention due to its typical properties such as excellent substrate adherence, piezoelectric properties, and high transparency in visible and near infrared region [4]. $\mathrm{ZnO}$ with Wurtzite structure is an n-type semiconductor material with both electrical and optical properties due to the deviation from the stoichiometry produced by the existence of intrinsic defects such as oxygen vacancies and $\mathrm{Zn}$ vacancies. The current study is motivated the desire to investigate the influence of oxygen on the structural, electrical and magnetic properties of thin doped $\mathrm{ZnO}$, and to identify a mean of better controlling the introduction of defects.

In this work, $\mathrm{Zn}_{0.98} \mathrm{Mn}_{0.02} \mathrm{O}$ thin layers were grown by pulsed laser deposition (PLD) technique. The structural properties of the grown samples were characterized by X-ray diffraction (XRD) and Raman techniques. Carrier's concentration and conductivity were estimated by Hall effect technique. The magnetic moment was measured as a function of temperature. The $\mathrm{O}_{2}$ pressure during the growth is shown to govern the structural and the electrical properties of the grown samples. Electronic and magnetic structures were calculated using the Korringa-Kohn-Rostoker coherent-potential-approximation (KKR-CPA) method [5].

\section{Experimental conditions}

The $\mathrm{Zn}_{0.98} \mathrm{Mn}_{0.02} \mathrm{O}$ thin films with thicknesses around 200-300 $\mathrm{nm}$ were deposited on glass substrate by PLD technique. The deposition was performed with the help of $\mathrm{KrF}$ laser $(248 \mathrm{~nm})$ in an oxygen atmosphere at room temperature. The used targets were $2 \% \mathrm{Mn}$ - doped 
$\mathrm{ZnO}$, prepared by standard ceramic procedures from $\mathrm{ZnO}$ and $\mathrm{MnO} 2$ powders [6]. The deposition of $\mathrm{Zn}_{0.98} \mathrm{Mn}_{0.02} \mathrm{O}$ was performed with energy density of about $5 \mathrm{~J} / \mathrm{cm}^{2}$ at frequency of $1 \mathrm{~Hz}$. Different oxygen pressures were applied during the growth. The details of the studied samples are summarized in table 1.

The structural properties of the films were determined by X-ray diffraction using $\mathrm{Cu} \mathrm{K \alpha}$ X-rays. The Raman spectra were obtained at room temperature in backscattering configuration with a Jobin-Yvon LabRaman HR equipped with a Multichannel air cooled $\left(-70{ }^{\circ} \mathrm{C}\right) \mathrm{CCD}$ detector with the $325 \mathrm{~nm}$ He-Cd laser line, and the Jobin-Yvon T64000 spectrometer equipped with a cooled CCD detector with the $514 \mathrm{~nm}$ laser line. An objective was used to focus the exciting light to $1 \mu \mathrm{m}$ on the surface of the sample. The electrical measurements were made with the standard four probes van der Pauw geometry. Low intensity currents $(1 \mu \mathrm{A}-1 \mathrm{~mA})$ were used to avoid the heating of the samples. Hall carriers and Hall mobility were measured at room temperature using a magnetic field of $1 \mathrm{~T}$. The magnetic properties were experimentally investigated by measurements versus temperature under magnetic field fixed at $0.07 \mathrm{~T}$. Measurements were performed in BS2 magnometer, developped in Luis Néel laboratory of Grenoble (France).

\section{Electronic structure calculation details}

Electronic structure calculations were performed within the fully relativistic (KKR) method [5]. To simulate the chemical disorder, coherent potential approximation (CPA) was considered for, and the exchange-correlation energy was used within the framework of the Local Spin Density Approximation. Muffin-tin form for the electron charge density and the crystal potential was assumed. Calculation were performed for $\mathrm{Zn}_{0.98} \mathrm{Mn}_{0.02} \mathrm{O}$ considered fully disordered systems where the $2 \mathrm{~b}$ site $(1 / 3,2 / 3,0)$ is randomly shared by both $\mathrm{Zn}$ and $\mathrm{Mn}$ atoms with occupation probabilities 0.98 and 0.02 for $\mathrm{Zn}$ and $\mathrm{Mn}$ atoms, respectively, while $2 \mathrm{~b}$ site $(1 / 3,2 / 3,0.345)$ is perfectly ordered and occupied by oxygen. Calculation were also performed 
on $\mathrm{Zn}_{0.98} \mathrm{Mn}_{0.02} \mathrm{O}_{0.8} \mathrm{Vc}_{0.2}(\mathrm{Vc}=$ vacancy) where $2 \mathrm{~b}$ sites are shared by oxygen and $\mathrm{Vc}$ vacancies with occupation probabilities 0.8 and 0.2 , respectively.

\section{Results and discussion}

The XRD patterns of the studied samples show dominant peak for the $\mathrm{ZnO}(002)$ plane. The results confirmed that the films are well oriented along the c-axis. Within the XRD detection limit no extra diffraction peaks from any $\mathrm{Mn}_{\mathrm{x}} \mathrm{O}_{\mathrm{y}}$ related to secondary phases or impurities can be detected in the XRD pattern. This indicates that these $\mathrm{Zn}_{0.98} \mathrm{Mn}_{0.02} \mathrm{O}$ thin films show a good cristallinity with a wurtzite structure and a c-axis preferred orientation. The full width at half maximum (FWHM) value of the XRD peak is influenced by many factors such as grain size, stress distribution, and crystal imperfection. Regardless of the influencing factor, the FWHM value is widely used as a negative indicator of film quality. In general, the grain becomes small with the addition of impurities to the matrix material due to the induced defects and imperfections that behave as the source for forming grain boundaries. The mean grain size (D) perpendicular to the reflecting plane in the film estimated by Scherer's formula. Fig. 1 shows the evolution of the grain size as a function of the oxygen pressure for the different studied samples. It is clearly seen that the size increases by increasing the pressure. These results indicate that $\mathrm{O}_{2}$ pressure during the PLD growth promotes the formation of big grains. At low $\mathrm{O}_{2}$ pressure, it seems that the lack of $\mathrm{O}_{2}$ generates dangling bond defects and promotes the formation of small cristallites grains.

In order to investigate the role of defects in the electrical properties of $\mathrm{Zn}_{0.98} \mathrm{Mn}_{0.02} \mathrm{O}$ thin layers, four probes resistivity and Hall measurements were performed. Fig. 2 shows the evolution of electron concentration $(n)$ and room temperature resistivity as a function of the growth oxygen pressure. For sample A (highest $\mathrm{O} 2$ pressure) it was not possible to estimate the carrier's concentration due to the high resistivity of the thin film (see inset Fig. 2). 
It is clear that $n$ decreases by increasing $\mathrm{O}_{2}$ pressure and then lowering defect's concentration. This could be explained by the fact that the thin $\mathrm{ZnO}$ films present oxygen vacancies excess which are passivated by increasing the $\mathrm{O}_{2}$ pressure during the growth. Another feature observed in this graph is the reverse tendency of carrier's mobility $(\mu)$ which decreases at low $\mathrm{O} 2$ pressure. Indeed, the increase in the $n$ value is generally associated with the decrease in the $\mu$ value because of the increased probability of carrier scattering due defects. In fact, high $\mathrm{n}$ values were obtained for low $\mathrm{O} 2$ pressure and then small $\mathrm{Zn}_{0.98} \mathrm{Mn}_{0.02} \mathrm{O}$ grain's size. $\mathrm{An}$ excess of $\mathrm{Zn}^{2+}$ donors could be responsible for the observed high $n$ at low $\mathrm{O}_{2}$ pressure. By increasing the pressure more oxygen vacancy are passivated and less free carriers are available. Our results are in good agreement with earlier finding which report that $\mathrm{O}$ vacancies and $\mathrm{Zn}$ interstitial are an important source of n-type conductivity in $\mathrm{ZnO}$ [7]. In fact, the oxygen depletion in the doped $\mathrm{ZnO}$ indicates the creation of oxygen vacancies. These oxygen vacancies are known to create shallow donor states and thus would add electrons to the system, doping the n-type carriers. We suggest that oxygen depletion owns the sole responsibility of charge neutrality factor in the lattice.

$\mathrm{ZnO}$ with wurtzite structure belongs to the space group $C_{6 v}^{4}$ with $A_{l}(z)+2 B_{1}+E_{l}(x, y)+2 E_{2}$ optical modes at the $\Gamma$ point of the Brillouin zone. The two $E_{2}$ modes are Raman active, the $A_{1}$ and $E_{1}$ modes are both Raman and infrared active, and the two $B_{1}$ modes are silent. Since the $A_{l}$ and $E_{l}$ modes are polar, they split into $L O$ and transverse optical $T O$ components. According to the selection rules in Raman spectra, only $E_{2}$ ( $E_{2}$ (low) and $E_{2}$ (high)) and $A_{l}(L O)$ phonon modes can be observed in the unpolarized Raman spectra of the caxis oriented $\mathrm{ZnO}$ thin film in the back scattering geometry, and their respective frequencies reported for bulk $\mathrm{ZnO}$ are 101, 437, and $574 \mathrm{~cm}^{-1}[8,9]$. Fig. 3a shows Raman spectra of the studied samples. Two major peaks are clearly seen centered at $527 \mathrm{~cm}^{-1}$ and $571 \mathrm{~cm}^{-1}$, with large bandwidth which could be explained [10] by Fröhlich electron-phonon scattering. The peak observed at $571 \mathrm{~cm}^{-1}$ in our spectra could be attributed to $A_{I}(L O)$. The small observed shift (3 
$\mathrm{cm}^{-1}$ ) comparatively to the bulk $A_{l}(L O)$ was already reported and explained by electron-phonon interaction $[11,12]$. The $A_{I}(L O)$ mode is known to be related to the defects such as oxygen vacancies, interstitial $\mathrm{Zn}$ in $\mathrm{ZnO}$. As a result, we think the appearance of $A_{l}(L O)$ mode at 571 $\mathrm{cm}^{-1}$ can be attributed to defects introduced by Mn doping. Additional mode (AMs) in the Raman spectra of Mn doped $\mathrm{ZnO}$ samples at $523 \mathrm{~cm}^{-1}$ was reported by Zhong et al. [13] and it was attributed to the $\mathrm{Zn}$ related vibration due to $\mathrm{Mn}$ incorporation in $\mathrm{ZnO}$. These peaks were considered to have an origin related to the vibration of Mn atoms. The occurrence of AMs is generally assigned to the activation of density of states due to the introduction of $\mathrm{Mn}$ on the network $[14,15]$. These experimental facts strongly support our argument that this mode should be attributed to Mn at substitutional sites. The inset of Fig. 3 shows the evolution of the ratio between the $A_{1}(\mathrm{LO})$ mode peak and the AM peak as a function of the grain size. It is well seen that this ratio increases with defects like dangling bonds and vacancies. This confirms that the increase on the intensity of $\mathrm{A}_{1}(\mathrm{LO})$ mode observed in our samples is related to defects induced in thin $\mathrm{ZnO}$ films by the incorporation of $\mathrm{Mn}$ ions. These results are in agreement with earlier finding by Exarhos et al. [16] who reported similar results concerning $A_{1}(L O)$ mode that they explained by the presence of $\mathrm{O}_{2}$ vacancies or $\mathrm{Zn}$ excess in the deposited films. Another interesting feature was observed in Raman spectra at low frequencies is the appearance of a broad peak centered around $183 \mathrm{~cm}^{-1}$ for samples grown at low $\mathrm{O}_{2}$ pressure and then high carriers concentration, as it is illustrated in Fig. 3b. In fact, this peak disappears for high resistive samples.

Oxygen depletion is a direct indicator of oxygen vacancies in the samples. However, upon heating in air the oxygen content is recovered. Annealing the samples in air at $600{ }^{\circ} \mathrm{C}$ seems to improve the crystalline quality of the samples by rearrangement of dense crystalline size. Fig. 4 shows the evolution of the Raman spectrum after annealing. It is well seen that the AM mode become more preponderant than the $A_{l}(L O)$ mode due to a better incorporation of $\mathrm{Mn}$ in $\mathrm{ZnO}$ structure. Moreover, the E1 (LO) peak becomes visible. This is demonstrates the 
improvement of the crystalline quality of the $\mathrm{ZnO}$ thin film by the incorporation of oxygen. Another low intensity Raman band at $380 \mathrm{~cm}^{-1}$ that matches the $A_{I}(T O)$ of $\mathrm{ZnO}$ which would be forbidden in this geometry. The existence of forbidden modes also could arise from $\mathrm{ZnO}$ grains no perfectly aligned along the c-axis after annealing.

Resonant Raman Scattering (RSS) has been proven to be an important tool for the study of basic physical properties of thin films and nanocrystal materials. It provides information about the electronic structure, electron-phonon coupling, and radiation coupling damage. The electron-phonon interaction could be straightly probed by the RRS when the exciting photon energy $\left(E_{i}\right)$ or the scattering photon energy $\left(E_{s}\right)$ is resonant with the electronic interband transition energy of the wurtzite $\mathrm{ZnO}\left(E_{g} \sim 3.3 \mathrm{eV}<E_{i}\right)$. Fig. 5 shows RSS spectra obtained under resonant excitation by the $325 \mathrm{~nm}\left(E_{i}=3.8 \mathrm{eV}\right)$ laser line. Up to $6 L O$ replica are observed for the samples grown at high $O_{2}$ pressure, while a higher background PL emission is observed for samples with high defect concentration. Normally, the increase of the density of structural defects leads to the redistribution of the recombination channels from radiative to non-radiative. However, we see that the PL band increases with defect concentrations (small grain size). The increase in UV emission suggests that more electron-hole pairs recombine through radiative recombination than non-radiative, which is in agreement with the decrease in resistivity.

As we have seen with Hall Effect measurements, these samples present high carrier's concentration. One of the reasons could be deep defect levels in the $\mathrm{ZnO}$ band gap when excited participate to the PL band. The electron-phonon coupling effect is enhanced when the exciting photon energy is resonant with the electronic states of the material. There are two mechanisms of electron-phonon coupling: (1) deformation potential (2) Fröhlich coupling. The deformation potential is effective when the short range interaction arises between the lattice displacement and the electrons, whereas, the Fröhlich coupling involves the long-range interaction generated 
by the macroscopic electric field associated with LO phonons. The presence of high carrier's concentration in samples grown at low $\mathrm{O} 2$ pressure confirms our arguments to explain the different behaviors observed in Raman spectra and we attributed it to electron-phonons interactions.

Fig. 6 show the magnetic moment against temperature for samples B and D. Sample B (grain size $\sim 51 \mathrm{~nm}$ ) shows a beginning of transition at $100 \mathrm{~K}$ while sample D (grain size $\sim 39 \mathrm{~nm}$ ) shows such transition at $30 \mathrm{~K}$. We were expecting magnetic transition at higher temperature for high defect samples. In fact, oxygen vacancies were suggested to play a major role in the inducement of ferromagnetism [17 - 19]. Recents reports also indicate that grain boundaries and intrinsic defects, especially the oxygen vacancies are important factor to enhance the ferromagnetism $[20,21]$. The absence of any clear effect of defects on the magnetic behavior for the studied samples could be related to low Mn doping.

We have been interested in electronic structure calculations in order to compute both magnetic moment in the cell and magnetic moment localized on $\mathrm{Mn}$ atom in disordered ferromagnetic $\mathrm{Zn}_{0.98} \mathrm{Mn}_{0.02} \mathrm{O}$ system. Density of state of both $\mathrm{ZnO}$ and $\mathrm{Zn}_{0.98} \mathrm{Mn}_{0.02} \mathrm{O}$ systems are reported in Fig. 7. As seen in Fig. 7(b), partial substitution of Zn by Mn introduces a polarization of DOS pointing out to ferromagnetic state of $\mathrm{Zn}_{0.98} \mathrm{Mn}_{0.02} \mathrm{O}$. DOS close to Fermi level is originating mainly from like-states $\mathrm{Mn}(3 d)$ which contribute only to major spins. The computed magnetic moment in the cell is found equal to $0.17 \mu_{\mathrm{B}}$ with substantial value of 3.04 $\mu_{\mathrm{B}}$ for magnetic moment localized on $\mathrm{Mn}$ atom. The observed lack of magnetism when oxygen pressure was applied during the growth could be explained by the expected vacancies presence on oxygen sites. These vacancies could enhance the films magnetism and their elimination induces a magnetism increase. Mounkachi et al. [22] performed similar calculations on $\mathrm{Zn}_{0.98} \mathrm{Mn}_{0.02} \mathrm{O}_{1-\mathrm{y}} \mathrm{N}_{\mathrm{y}}$ and reported that the magnetism is sensitive the hole concentrations on site oxygen. To shed light on this magnetism absence in $\mathrm{Zn}_{0.98} \mathrm{Mn}_{0.02} \mathrm{O}$, we performed calculations 
with $\mathrm{Vc}$ (vacancies) on oxygen sites; so that the system is $\mathrm{Zn}_{0.98} \mathrm{Mn}_{0.02} \mathrm{O}_{1-\mathrm{y}} \mathrm{V}_{\text {cy }}$ with $\mathrm{y}=0.1$. As expected result, magnetism increases, which means magnetic moment in the cell changes from 0.17 to $0.18 \mu_{\mathrm{B}}$ while Mn magnetic moment increases from 3.04 to $3.15 \mu_{\mathrm{B}}$.

\section{Conclusion}

Thin $\mathrm{Zn}_{0.98} \mathrm{Mn}_{0.02} \mathrm{O}$ films were grown by PLD technique under $\mathrm{O} 2$ pressure. The grown samples were characterized by XRD, Raman spectroscopy and Hall effect. The structural and electrical properties of the grown films were shown to be dramatically influenced by the growth $\mathrm{O} 2$ pressure. This influences the $\mathrm{Zn}_{0.98} \mathrm{Mn}_{0.02} \mathrm{O}$ grain's size and the carrier's concentration in the films. No effect was observed for the magnetic properties and this conclusion is confirmed by electronic structure calculations. Indeed, these calculations point out that the vacancies presence on oxygen sites enhances magnetism in the $\mathrm{Zn}_{0.98} \mathrm{Mn}_{0.02} \mathrm{O}$ system.

\section{Acknowledgement}

This work has been partially funded through the projects PTDC/FIS/098943/2008 financed by Portuguese Foundation for Science and Technology (FCT) and by European Commission through project ELIARE NETWORK SUDOE INTERREG IV B (2009-2011), and the Scientific and Technological Cooperation Program between Portugal (FCT) and Morocco (CNRST)-2010/2011. SL thanks FCT for the financial support through the grant SFRH/BPD/26532/2006. 
References:

[1] T. Dietl, H. Ohno, F. Matsukura, J. Cibert, and D. Ferrand, Science 287, 1019 (2000)

[2] G. Lawes, A. S. Risbud, A. P. Ramirez, R. Sechardi, Phys. Rev. B 71, 045201 (2005)

[3] A. Khodorov, S. Levichev, A. G. Rolo, O. Karzazi, A. Chahboun, M. R Correia, R. J. Novak, C. J. Tavares, D. Eyidi, J.-P. Rivière, M. F. Beaufort, N. P. Barradas, E. Alves, S. Lanceros-Mendez and M. J. M. Gomes, Nanotechnology 21, 505705 (2010)

[4] F. Zhuge, L. P. Zhu, Z. Z. Ye, D. W. Ma, J. G. Lu, J. Y. Huang, F. Z. Wang, Z. G. Ji, and S. B. Zhang, Appl. Phys. Lett. 87, 092103 (2005)

[5] H. Akai, J. Phys. Conden. Matter 1, 211 (1989)

[6] O. Karzazi, A. Chahboun, A. G. Rolo, E. K. Hlil, N. Benzakour, K. Bouslykhame, A. Hourmatallah, S. Levichev, A. Khodorv, and M. J. M. Gomes, Eur. Phys. J. Appl. Phys. 50, $3080(2010)$

[7] Y. S. Kim, C. H. Park, Phys. Rev. Lett. 102, 086403 (2009)

[8] F. Decremps, J. Pellicer-Porres, A. Marco Saitta, J. C. Chervin, and A. Polian, Phys. Rev. B 65, $092101(2002)$

[9] P. Dahan, V. Fleurov, K. Kikoin, J. Phys. : Condens. Matter 9, 5355 (1997)

[10] J. A. Sans, G. Martinez-Criado, J. Susini, R. Sanz, J. Jansen, I. Minguez, M. HernandezVelez, A. Labrador, P. Carpentier, J. Appl. Phys. 107, 023507 (2010)

[11] C. W. Zou, H. J. Wang, M. L. Yi, M. Li, C. S. Liu, L. P. Guo, D. J. Fu, and T. W. Kang, Appl. Surf. Sci. 256, 2453 (2010)

[12] K. A. Alim, V. A. Fonoberov, M. Shamsa, A. A. Balandin, J. Appl. Phys. 97, 124313 (2005)

[13] H. Zhong, J. Wang, X. Chen, Z. Li, W. Xu, and W. Lu, J. Appl. Phys. 99, 103905 (2006)

[14] J. M. Calleja and M. Cardona, Phys. Rev. B 16, 3753 (1997) 
[15] Ü. Özgüra, Ya I. AlivovI, C. Liu, A. Tekeb, M. A. Reshchikov, S. Doğanc, V. Avrutin, S-J Cho, and H. Morkoçd, J. Appl. Phys. 98, 051301 (2005)

[16] G. J. Exarhos and S. K. Sharma, thin Solid Films 270, 27 (1995)

[17] C. D. Pemmaraju, R. Hanafin, T. Archer, H. B. Braun, and S. Sanvito, Phys. Rev. B 78, $054428(2008)$

[18] T. Tietze, M. Gacic, G. Schutz, G. Jakob et al., New J. Phys. 10, 055009 (2008)

[19] A. Sundaresan, R. Bhargavi, N. Rangarajan, U. Siddesh, and C. N. R. Rao, Phys. Rev. B 74, $161306(2006)$

[20] M. D. McCluskey and S. J. Jokela, J. Appl. Phys. 106, 071101 (2009)

[21] B. B. Straumal et al., Phys. Rev. B 79, 205206 (2009)

[22] O. Mounkachi, A. Benyoussef, A. El Kenz, E. H. Saidi, E. K. Hlil, J. Magn. Magn. Mater. 320, 2760 (2008) 


\section{Captions:}

Table 1: Details of the studied samples.

Fig. 1: Evolution of the grain size as a function of $\mathrm{O}_{2}$ growth pressure.

Fig. 2: Evolution of electron concentration as a function of $\mathrm{O}_{2}$ pressure. The inset shows the evolution of the resistivity against $\mathrm{O}_{2}$ pressure.

Fig. 3a: Raman spectra of samples A and D. The dashed lines indicate the position $1 L O$ and $A M$ modes. The inset shows the evolution of intensity ratio of $1 L O$ mode and $A M$ mode against grain size.

Fig. 3b: Raman spectra of samples $A$ and $D$ for low frequencies.

Fig. 4: Raman spectra of an as grown sample $(A)$ and after annealing in air at $600{ }^{\circ} \mathrm{C}$

Fig. 5: Resonant Raman spectra of samples $A, D$, and annealed $A$ sample.

Fig. 6: Magnetic moment as a function of the temperature for samples $B$ and $D$.

Fig. 7: Total DOS of $\mathrm{ZnO}(\mathrm{a})$; Total DOS and $l$-decomposed DOS of like-states $\mathrm{Mn}(3 d)$ in the ferromagnetic $\mathrm{Zn}_{0.98} \mathrm{Mn}_{0.02} \mathrm{O}$ for spin up and spin down (b) 
Table 1: Details of the studied samples.

\begin{tabular}{cccccc}
\hline Sample & $\begin{array}{c}\text { Oxygen pressure } \\
\mathrm{P}\left(10^{-3} \mathrm{mbar}\right)\end{array}$ & $\begin{array}{c}\text { FWHM } \\
(\text { degree })\end{array}$ & $\begin{array}{c}\text { Grain sizes } \\
\mathrm{D}(\mathrm{nm})\end{array}$ & $\begin{array}{c}\text { Resistivity } \\
\rho(\text { Ohm.cm })\end{array}$ & $\begin{array}{c}\text { Carriers } \\
\mathrm{n}\left(10^{20} \mathrm{~cm}^{-3}\right)\end{array}$ \\
\hline $\mathrm{A}$ & 0.05 & 0.203 & 71.3 & $5.210^{3}$ & very high resistance \\
\hline $\mathrm{B}$ & 0.025 & 0.282 & 51.4 & $1.610^{-2}$ & 0.73 \\
\hline $\mathrm{C}$ & 0.01 & 0.319 & 45.3 & $4.710^{-3}$ & 0.69 \\
\hline $\mathrm{D}$ & 0.005 & 0.366 & 39.6 & $4.310^{-3}$ & 1 \\
\hline
\end{tabular}




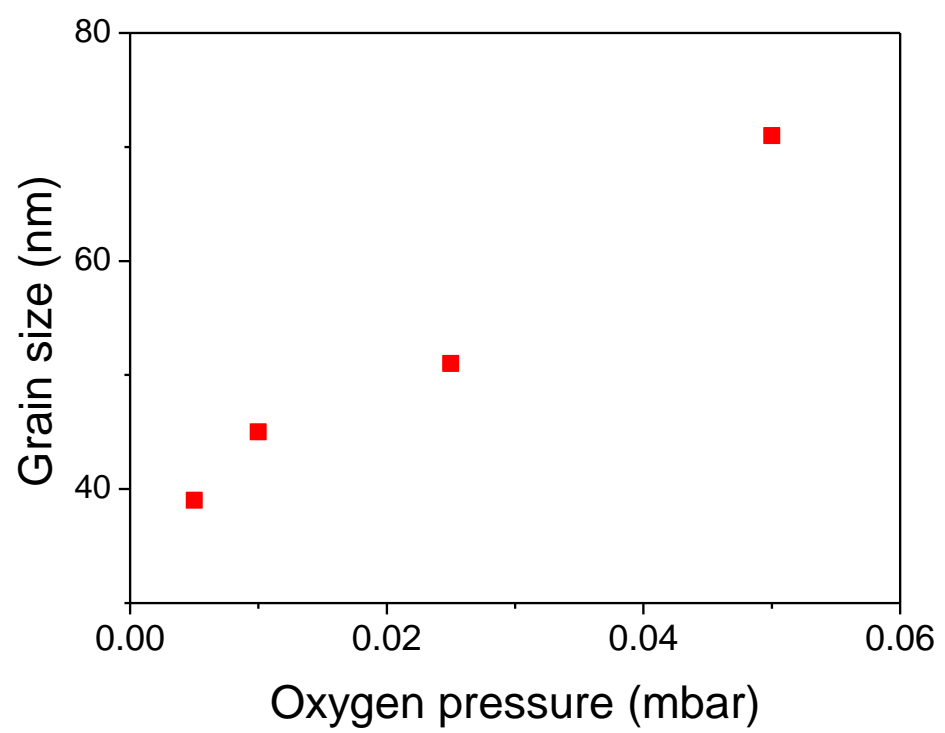

Fig. 1: Evolution of the grain size as a function of $\mathrm{O}_{2}$ growth pressure. 


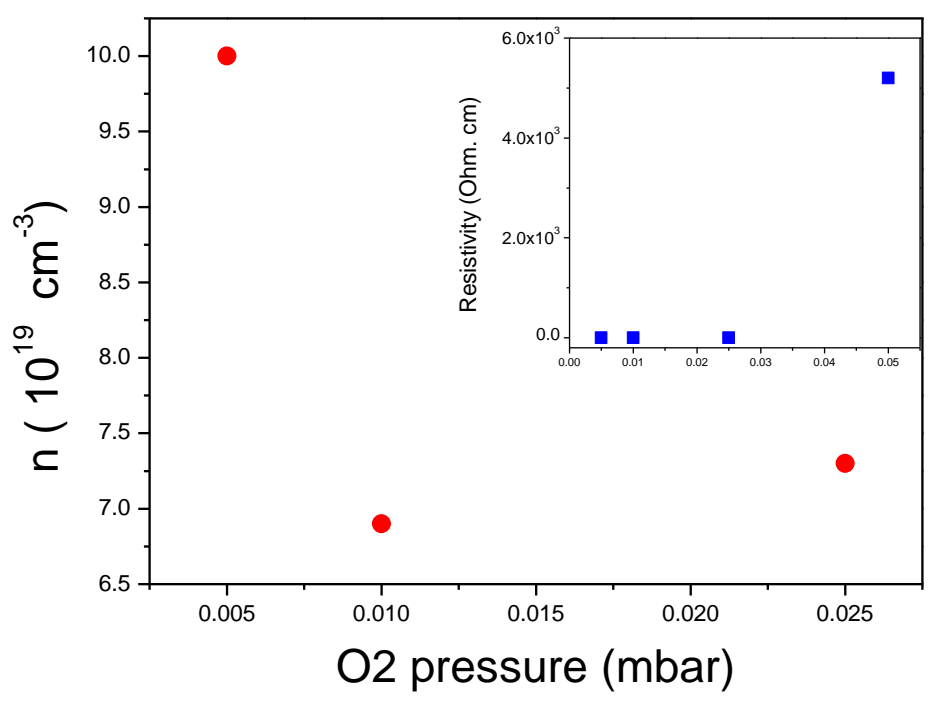

Fig. 2: Evolution of electron concentration as a function of $\mathrm{O}_{2}$ pressure. The inset shows the evolution of the resistivity against $\mathrm{O}_{2}$ pressure. 


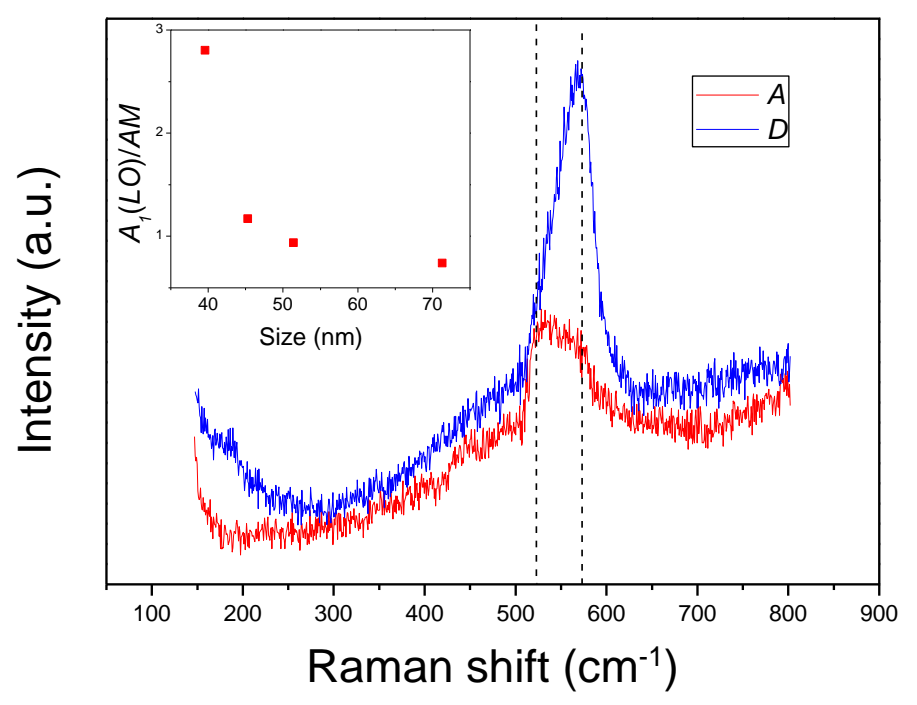

Fig 3a: Raman spectra of samples $\mathrm{A}$ and $\mathrm{D}$. The dashed lines indicate the position $1 L O$ and $A M$ modes. The inset shows the evolution of intensity ratio of $1 L O$ mode and $A M$ mode against grain size.

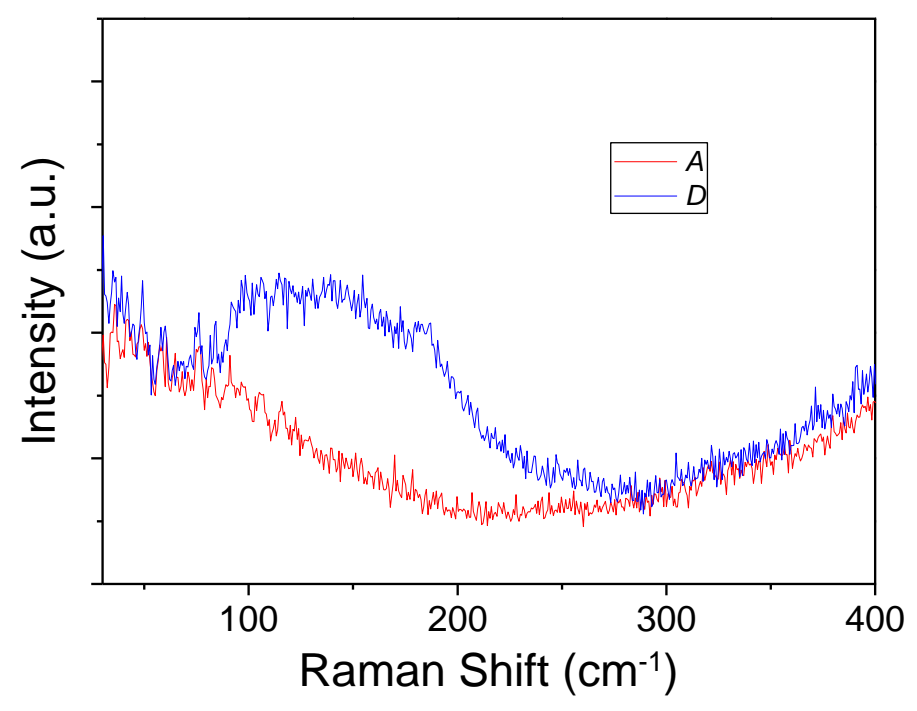

Fig. 3b: Raman spectra of samples $A$ and $D$ for low frequencies. 


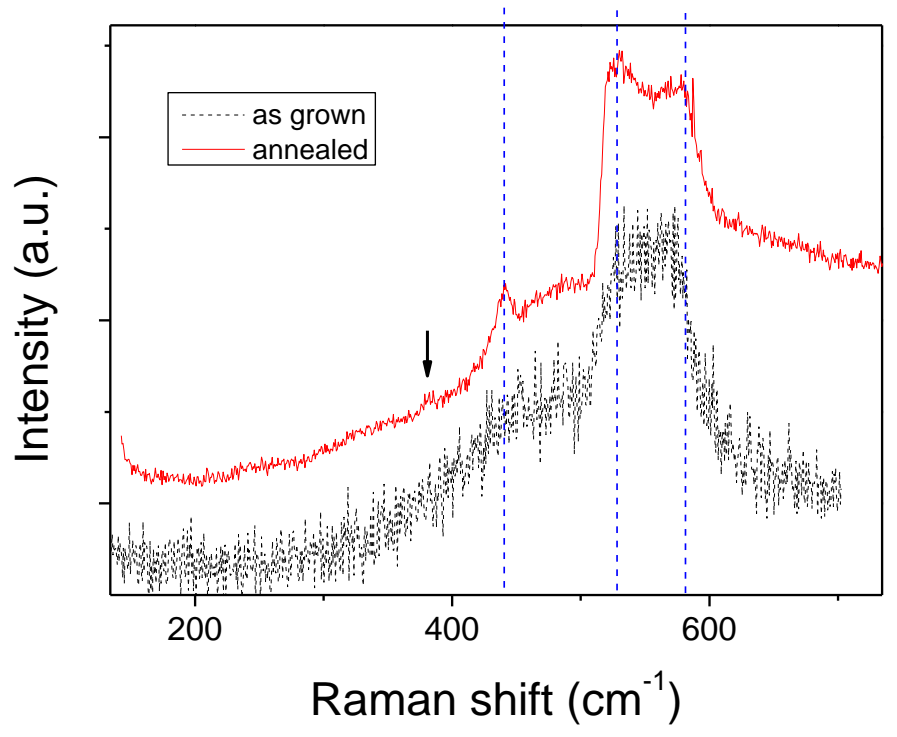

Fig. 4: Raman spectra of an as grown sample $(A)$ and after annealing in air at $600{ }^{\circ} \mathrm{C}$ 


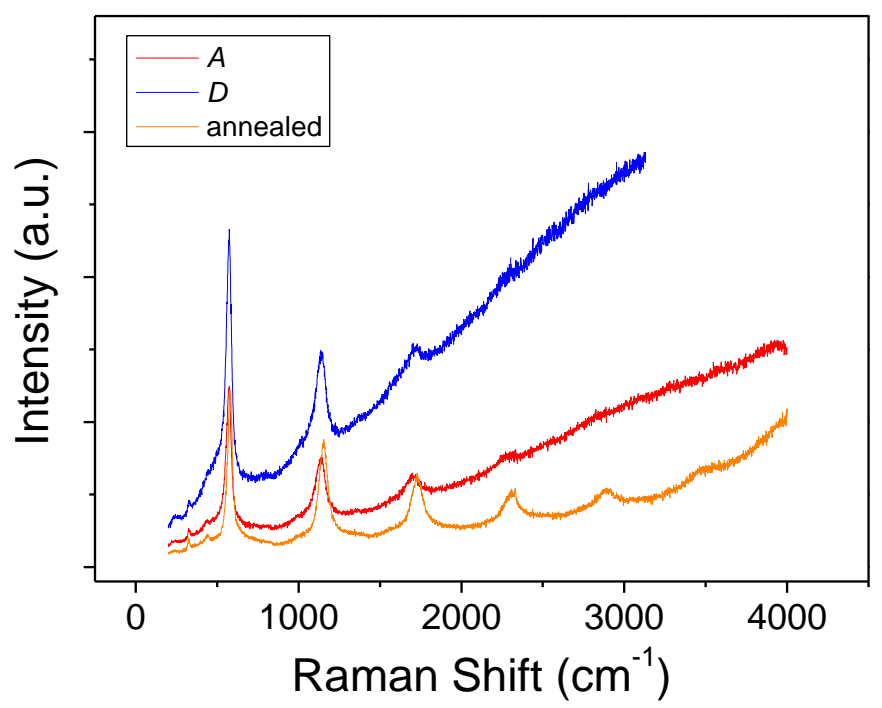

Fig. 5: Resonant Raman spectra of samples $A, D$, and annealed $A$ sample. 


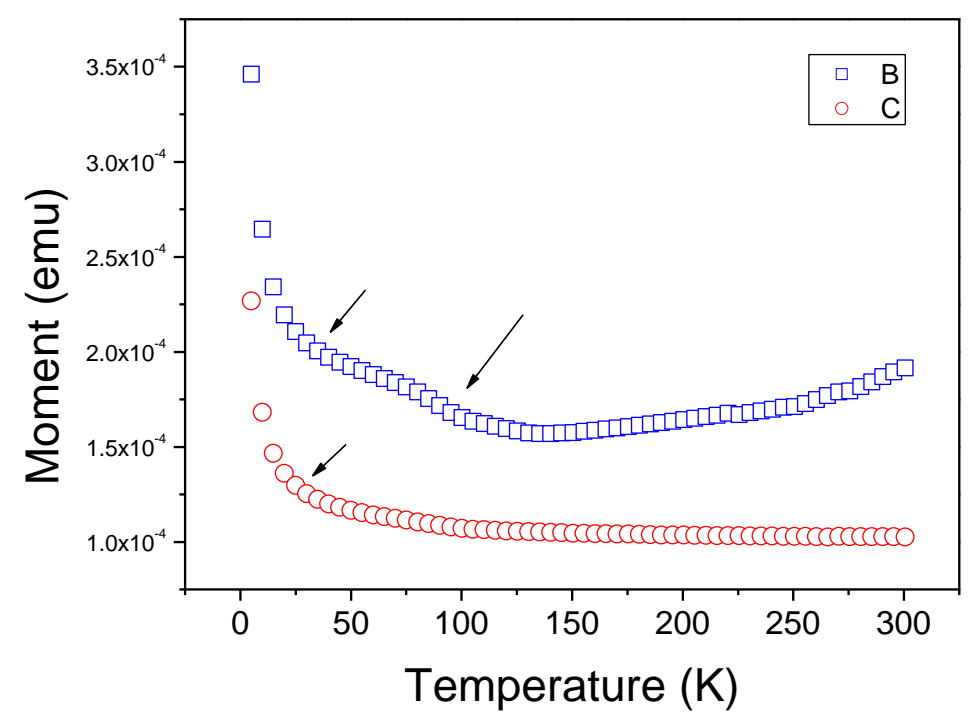

Fig. 6: Magnetic moment as a function of the temperature for samples $B$ and $D$. The arrows indicate magnetic transitions. 


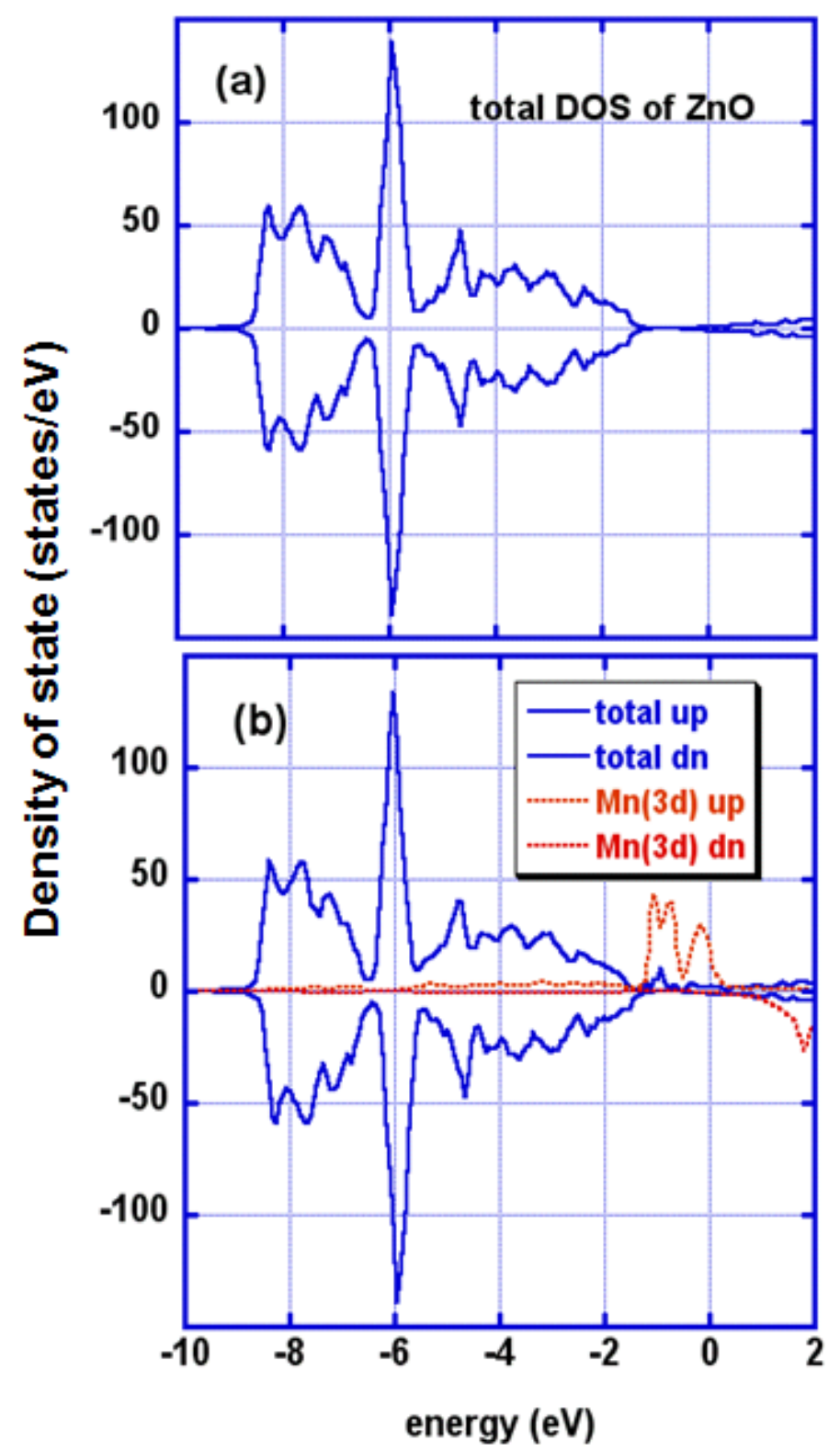

Fig. 7: Total DOS of $\mathrm{ZnO}$ (a); Total DOS and $l$-decomposed DOS of like-states $\mathrm{Mn}(3 d)$ in the ferromagnetic $\mathrm{Zn}_{0.98} \mathrm{Mn}_{0.02} \mathrm{O}$ for spin up and spin down (b) 